\title{
The Family Health Strategy and Its Relevance to Geriatric Immunisation Campaigns Against COVID-19 in Brazil
}

\author{
Roberth Steven Gutiérrez-Murillo ${ }^{1,2 *}$ (D)
}

${ }^{1}$ Department of Geriatrics and Gerontology, European University of the Atlantic, SPAIN
${ }^{2}$ Latin American Institute of Nature and Life Sciences, Federal University for Latin American Integration, BRAZIL
${ }^{*}$ Corresponding Author: stevengumu@gmail.com

Citation: Gutiérrez-Murillo RS. The Family Health Strategy and Its Relevance to Geriatric Immunisation Campaigns Against COVID-19 in Brazil. Electron J Gen Med. 2022;19(2):em358. https://doi.org/10.29333/ejgm/11579

\section{ARTICLE INFO}

Received: 30 Dec. 2021

Accepted: 16 Jan. 2022

\begin{abstract}
The pandemic caused by the emergence of the new coronavirus disease 2019 (COVID-19) at the beginning of 2020 has set a new reality for public health systems, especially in terms of health care for older adults. In Brazil, there was a need to reinforce actions conceived within primary health care, precisely because it is the ideal field for the development of local, state and national immunisation campaigns against COVID-19. The geriatric immunisation campaign against COVID-19 was carried out through the Family Health Strategy, precisely because it is the preferred model of care. In a few months, a reduction in morbidity and mortality rates was observed in all Brazilian municipalities, which reinforced the importance of this model of management and health care for older persons.
\end{abstract}

Keywords: health of older adults, public health, aging epidemiology

Dear Editor,

The Brazilian Unified Health System is recognised worldwide as one of the largest public health systems, guided by the pillars of comprehensiveness, equity and universality in health. In turn, the Family Health Strategy (hereafter FHS) represents the greatest Brazilian effort to validate and reinforce the universal right to health, which is an inalienable and non-transferable right of every citizen, as well as an immediate responsibility of the State.

Briefly explained, the FHS is a strategy for expansion, qualification and consolidation of primary care as it favours a reorientation of the work process with greater potential to deepen the principles, guidelines and foundations of primary care, to expand the resoluteness and impact on the health situation of people and communities, and to provide an important cost-effectiveness ratio. In order to achieve greater coverage and effectiveness of the proposed interventions, the FHS is organised according to operational guidelines, among which the following should be highlighted: person-centred care, resolvability, long-lasting care, organisation and coordination of the care network [1].

In Brazil, as in the rest of the world, the new coronavirus disease 2019 (hereafter COVID-19) pandemic brought about a series of organisational contingencies for health services that, added to the high morbidity and case fatality rates in the older adult population, ended up mucking the comprehensiveness of the services and programmes offered to this public during 2020 and, more slightly, during the beginning of 2021 [2]. According to the official COVID-19 monitoring site (MonitoraCOVID-19), elaborated and managed by the Fundação Oswaldo Cruz (FIOCRUZ), as of 12 December 2021, there were a total of 22,167,781 confirmed cases and 616,251 deceases, which translates into a lethality rate of $2.78 \%$, one of the highest rates observed in the region [3].

Despite the statistics being drastic on the national scene, the immunisation interventions enacted since the beginning of 2021 played an extremely important role in containing and reducing COVID-19 infections and deaths. Initially, priority was given to health professionals working on the frontline against COVID-19, as they were considered to be the main risk group. Following this, older persons were listed as the first population segment to be immunised. Such decision not only considered the pathophysiological aspects of this public, but also obtained legal support through national decrees that defended this action based on the lethality coefficient in this segment. Even within this age-group, there was a risk stratification, which prioritised those individuals who were older, with the presence of respiratory, cardiac and immunological comorbidities, mainly.

The benefits that the FHS brought to the management, planning and implementation processes of geriatric immunisation campaigns against COVID-19 were mainly reflected in the coordination and accountability of care by primary health care teams. Each health team was in charge of the territorial mapping of the registered older adults, either by telephone or by active search in their homes.

At the micro level of municipal health management, the organisational and coordination mechanisms in the basic health units made it possible to reinforce the COVID-19 prevention guidelines, making home visits an excellent tool to avoid overcrowding in health facilities [2, 4]. As a matter of fact, home visits promoted the integrity of older adults who did not have the locomotor capacities to access the immunisation posts, as in the case of people who were bedridden or had 
disabling illnesses. An explanatory aspect for the high immunisation rate is the strong relationship that the FHS teams maintain with the users in their coverage territories. Furthermore, this was also reflected in the reduction of institutional costs, and the rapid location of people at higher risk for the disease [4].

Although there are many challenges that COVID-19 has imposed on health services in Brazil, it is fair to note the efforts made. In this sense, the geriatric immunisation campaign has been one of the main triumphs and one of the most significant preventive events for the country.

Funding: No funding source is reported for this study.

Declaration of interest: No conflict of interest is declared by author.

\section{REFERENCES}

1. Brazil Ministry of Health. Ordinance no. 2.436, of September 21, 2017. Approves the National Policy for Primary Care, establishing the review of guidelines for the organization of Primary Care, within the scope of the Unified Health System (SUS). Available at: https://bvsms.saude.gov.br/bvs/saudelegis/gm/2017/prt2 436_22_09_2017.html

2. Werneck GL, Carvalho MS. The COVID-19 pandemic in Brazil: Chronicle of a health crisis foretold. Cad Saude Publica. 2020; 36(5):e00068820. https://doi.org/10.1590/ 0102-311X00068820 PMid:32402007

3. Fundação Oswaldo Cruz (FIOZCRUZ). MonitoraCOVID-19: 12 December 2021. Available at: https://bigdatacovid19.icict.fiocruz.br/ (Accessed 12 December 2021)

4. Menezes AMP, Hallal PC, Silveira MF, et al. Influenza vaccination in older adults during the COVID-19 pandemic: A population-based study in 133 Brazilian cities. Cien Saude Colet. 2021;26(8):2937-48. https://doi.org/10.1590/ 1413-81232021268.09382021 PMid:34378687 